\title{
A Critical Evaluation of Nearpod's Usefulness in Teaching K-12 Biology Science Online Classroom
}

\author{
Junhua Xian ${ }^{1 *}$ \\ ${ }^{1}$ Faculty of Education, Monash University, Wellington Road, Clayton, VIC, 3800, Australia. \\ ${ }^{*}$ Corresponding author. Email: jxia0028@student.monash.edu
}

\begin{abstract}
The outbreak of Covid-19 has shifted the locus of teaching activity from the traditional teacher to the Internet. We strive for better educational aid for in-service teachers everywhere globally to help students have a better teaching and learning experience. Nearpod is a great platform to bring content and assessment into the K-12 biology and science classroom. In this article, TPACK (Technological Pedagogical Content Knowledge) is used as the theoretical basis for analysis and discussion to explore the potential benefits of Nearpod in the K-12 bioscience classroom. After using Nearpod for online instruction, I interviewed the students who participated in the relevant courses and compiled and analyzed their responses to draw supporting conclusions. Synchronous engagement in secondary biology classrooms brings a better classroom experience for teachers and students. It gives us a more authentic classroom experience, especially during the special times when teaching has to be done online. And the synchronous form of online learning and assessment can help teachers track student learning, and the Online Simultaneous Learning and Assessment Model (OLASF) impacts student performance. Moreover, the Nearpod platform motivates students to become more active in classroom activities. The real-time interactive classroom design ensures class participation and prevents students from using other programs in class to disrupt the class and the learning process to a certain extent. Student responses confirmed the relevance and value of Nearpod in the online classroom.
\end{abstract}

Keywords: Nearpod, K-12 classroom, Biology and science, Educational technology.

\section{INTRODUCTION}

In 2020, public health issues facing humanity (covid19) led to a shift in teaching and learning activities from real to online [1]. The use of the Internet for teaching and learning activities and how to make the learning experience better for students has become an issue of great concern for educators in the recent decade [2]. As a secondary school biology teacher, I have to teach through an online platform. Also, I have to teach through an online platform. How to give students an authentic classroom experience and how to provide timely feedback to students are my main concerns compared to the traditional online teaching model.

At the beginning of this paper, I will explain the theoretical framework of the article study, TPACK (Technological Pedagogical Content Knowledge), which is knowledge about the complex relationship between technology, pedagogy, and subject matter that helps teachers develop effective teaching methods and strategies for specific contexts [3]. Secondly, I will analyze the potential advantages of Nearpod's application in secondary school biology science classrooms. Synchronous engagement in secondary biology classrooms brings a better classroom experience for teachers and students. It gives us a more authentic classroom experience, especially during the special times when teaching has to be done online. The synchronous form of online learning and assessment can help teachers keep track of students' learning status, and the online synchronous learning and assessment model (OLASF) has a certain degree of impact on students' learning performance. And Nearpod platform motivates students to become more active in classroom activities. Thirdly, some shortcomings of Nearpod in the application are discussed, and some suggestions for implementation are given. There are some constraints to the development of distance education, such as cost, evaluation system, and infrastructure. Finally, based on the above content, I will conclude that a comparison of the test scores of lowerperforming students before the use of Nearpod revealed more significant academic improvement. And student 
responses confirmed the relevance and value of Nearpod in the online classroom.

\section{THEORETICAL FRAMEWORK}

TPACK (Technological Pedagogical Content Knowledge) is the guiding framework used in this article. TCK (Technological Content Knowledge), which refers to the interrelationship between technological knowledge and disciplinary content knowledge, is often influenced and limited by various technologies and their representations and functions [3]. PCK (Pedagogical Content Knowledge) is knowledge about organizing the representation of a particular topic, problem, or issue, adapting it to learners' diverse interests and abilities, and presenting it in instruction [3]. TPK (Technological Pedagogical Knowledge) is knowledge about how technology supports or limits instructional practices. TPACK refers to knowledge about the complex relationships among technology, pedagogy, and subject matter that help teachers develop effective teaching methods and strategies for specific contexts [3]. TPACK is an emerging type of knowledge that goes beyond mere subject matter content knowledge, pedagogical knowledge, and technological knowledge and exists within the dynamic interrelationship of these three types of knowledge.

\section{POTENTIAL ADVANTAGES OF IMPLEMENTING NEARPOD}

\subsection{Synchronized interactive classroom participation builds real classroom senses}

Synchronous engagement in secondary biology classrooms brings a better classroom experience for teachers and students. It gives us a more authentic classroom experience, especially during the special times when teaching has to be done online. Different students have different preferences for synchronous and asynchronous participation [4]. Usually, the result of these different preferences is that students will perform differently academically. In one survey, students were asked to make a pre-class choice between their preference for online education, i.e., synchronous remote participation (real-time classroom interaction via the Nearpod platform) and asynchronous remote participation (such as the previously popular flipped classroom model). The study results showed that students who chose synchronous remote participation accounted for $90 \%$ of the respondents. At the same time, these participants also indicated that synchronous remote participation would give them a sense of classroom engagement and an increased sense of belonging in classroom instruction [1]. These respondents felt that synchronous remote participation in the classroom gave them the feeling of a traditional real classroom. They preferred this online interactive model that increased their sense of classroom participation compared to previous online education that faced cold electronic devices and virtual teacher influence.

While some students prefer asynchronous participation in the classroom and are more accustomed to the flexibility it offers, this flexibility is reflected in the fact that they can control their own learning pace and schedule their learning freely. It is easy to see that the long-standing traditional asynchronous participation model can accustom some students to learning methods they have long been comfortable with. Over time, synchronous classroom participants dominate, and asynchronous classroom participation preferences can easily be marginalized in challenging environments [2]. The result of this marginalization can then directly lead to lower student motivation. Moreover, we have to admit that asynchronous classroom participation does help students self-adjust to their own pace of learning. In the past, this initiative has also helped, to some extent, those students who were not well engaged in traditional faceto-face classes to accomplish good remediation after class.

Although asynchronous participation in the classroom has the advantage of providing students with a free and flexible learning atmosphere, there are significant differences in the impact of the two different types of participation on students. The study indicated that students who chose synchronous remote classroom participation had significantly higher academic performance averages than their peers. In response, a student who opted for synchronous classroom participation was interviewed, in which he stated:

"I like the real-time interactive classroom model, although sometimes I am not comfortable asking the teacher questions in class, I can ask my group members for help. I felt the joy of teamwork in this process. Without this kind of real-time interaction, if I encounter any problem in the process of learning, I may completely forget about it after a while. It is because many of my questions were answered in time during the study process that I could better answer the questions on the test paper during the exam."

Indeed, the timely interaction of synchronous participation can provide students with more opportunities for communication and collaboration. This is one of the advantages of using the Nearpod application in online teaching.

\subsection{Interactive feedback from teachers and students is effective in the classroom}

The synchronous form of online learning and assessment can help teachers keep track of students' learning status, and the online synchronous learning and assessment model (OLASF) has a certain degree of impact on students' learning performance. The traditional 
PowerPoint teaching model is a stage in technologization in the field of education. This teaching stage belongs to the transitional period of educational reform, which will be gradually optimized or even replaced with changes in science and technology [5]. It cannot be denied that the traditional PowerPoint teaching model is a model of success in education with the help of technology tools [6]. However, if this teaching model has been used in online teaching, there will be some drawbacks, such as teachers and students cannot interact with each other, and students and teachers cannot communicate with each other in time [7]. The teacher cannot understand the students' learning situation in class through real-time testing. Unlike the traditional PowerPoint teaching model, the Nearpodbased real-time interactive teaching platform provides good two-way feedback to teachers and students.

Moreover, the impact of feedback on learning is intuitive, but its presence can have both positive and negative effects. As one of the main influences on learning and achievement, different types of feedback can have different effects [8]. I claim that there are four major levels and that the level at which feedback is directed influences its effectiveness [8]. The first level of feedback may include directions to acquire more, different, or correct information; the second level is more directly aimed at the processing of information or learning processes requiring understanding or complete the task, and the self-regulation level includes greater skill in self-evaluation or confidence to engage further on a task. The fourth level is too often unrelated to performance on the task [8]. In addition, three questions to untangle some thorny feedback issues, such as the timing of feedback, immediate error correction during task acquisition (FT), can result in faster acquisition rates. In contrast, immediate error correction during fluency building can detract from the learning of automaticity and the associated strategies of learning (FP) [8].

However, some differing views see some problems associated with educators' over-reliance on educational support workers. They insist that if there is a lack of systematic assessment criteria, it is somewhat inappropriate to allow teachers to judge students' academic performance with the help of tools. They worry that the advent of educational aids will cause educators to lose sight of the relationship between students, teachers, and content. Nearpod, however, avoids this by allowing teachers and students to interact with each other at home, serving as a medium to provide continuous feedback to teachers and students, a good way to collect evidence of students' cognitive and non-cognitive achievements in online instruction, and better able to help students interact with each other in the classroom, creating a virtuous cycle of teachers, students, and assessment [7]. Feedback can be seen as an extension of the teacher's instruction. Feedback is a clear, purposeful, instructive, and targeted suggestion that motivates learners to take the initiative in processing information, and the presence of feedback encourages students to learn from their mistakes. At the same time, when feedback is effectively integrated with classroom instruction, it can contribute well to student learning. Students, especially with the help of timely feedback, can better build their interest in learning and gain a greater sense of learning accomplishment.

\subsection{Nearpod boots student motivation}

Nearpod platform motivates students to become more active in classroom activities. First, the real-time interactive classroom design ensures class participation and prevents students from using other programs in class to disrupt the class and the learning process to a certain extent [9]. One student who regularly browsed other social apps in class revealed to me that:

"When I was first introduced to this model, I was particularly surprised, and after using it, I realized the difference between this Nearpod platform and other teaching software. Unlike other teaching aids, where my motivation decreases with time, Nearpod's real-time interaction forced me to pay attention to the class because I did not know when I would be asked to complete a task. Although it seems a bit forced at times, it has done a good job of eliminating my vice of browsing various social apps in class."

Second, the Nearpod app made the class-competitive and fun [10]. When students are asked to present their answers in front of a large group of people, they tend to concentrate more on thinking and to learn to perform well because they do not want to make any mistakes [11]. This may add a little bit of pressure to them, but it is not all bad when the pressure is properly applied [12]. A moderate amount of pressure to learn can be beneficial by keeping students in an emotionally stimulating state, enlivening their thinking skills, and enhancing their reaction time [13]. If there is no stress and the body and mind are relaxed, the individual's potential will not be realized [13]. It is worth noting that too much pressure to study can have many negative effects. These negative effects can negatively impact the individual's perception, mood, and behavior, causing a range of adverse psychological reactions and physical symptoms such as stress, irritability, and anxiety [13].

However, the large-scale use of technology-based tools has to consider several realities. First, Nearpod needs mobile devices as a medium to support its proper functioning. Given the requirements of mobile devices for Internet stability, it needs to be proven whether Internet stability can meet the daily learning needs of students in some remote areas. If the Internet connection is not stable enough, it will bring students a bad experience, which is difficult to ensure that students will not resist the Nearpod platform due to Internet technology. Secondly, the Nearpod platform is typed 
through a keyboard or electronic pen when interacting in real-time, which is slower when writing on a mobile device such as a phone or tablet than traditional pen and paper writing [12]. This requires that teachers allow more time for students to key in during classroom instruction. In this way, it appears that the allocation of classroom time then needs to be adjusted by the teacher accordingly.

Although technical issues are a potential impediment to Nearpod's rollout, this does not affect the popularity of Nearpod with more teachers and students in the future. These technical problems will be solved with the rapid development of technology, and Nearpod has a clear effect on improving students' learning levels and academic performance. In particular, a comparison of lower-performing students' test scores before using Nearpod revealed more significant academic improvement. Student responses confirmed the relevance and value of Nearpod in the online classroom. They reported that the results of the synchronized interactive tests helped them perform better in class because the realtime feedback helped them correct classroom errors promptly [10].

\section{DISCUSSION}

Online distance education gives students more opportunities and ways to learn, especially in special times, such as when all of humanity is facing unexpected public health problems at the same time (COVID-19) [1]. The advantages of distance education come to the fore. Compared with traditional school education, distance education has the advantages of industrialization, openness, resource sharing, pragmatism and flexibility. At the same time, there are some constraints to the development of distance education, such as cost, evaluation system, and infrastructure. It is urgent to investigate further how online education platforms and tools can effectively help educators conduct effective teaching and learning activities. And the traditional online teaching model may have the disadvantage of lacking synchronous interaction. Students and teachers cannot communicate in class on time, and teachers will not get timely feedback on classroom teaching. If the teacher gets timely feedback related to students' learning, the teacher will make changes in the teaching process accordingly [6]. The Nearpod platform offers the possibility of simultaneous teacher-student interaction for online assessments. This real-time interaction allows for a significant increase in student engagement and motivation.

In addition, the use of Nearpod can support teaching and learning considering that students have different preferences, and therefore all references should be taken into account by the teacher. For students with asynchronous participation preferences who insist on their preferred learning mode, teachers can provide good guidance during the transition period. This process should allow students to gradually understand and accept the fun and advantages of synchronous participation in the classroom [14]. Once they begin to truly understand the convenience and advantages of synchronous participation in the classroom, they will gradually accept the model. This is an inevitable problem when teaching with educational aids, so the launch of a synchronous interactive teaching platform like Nearpod should consider the preferences of different students, and it is one of the best choices to promote synchronous participation and asynchronous participation in parallel at the beginning, which will give students enough buffer time to adapt and accept.

Moreover, the use of the Nearpod platform in the classroom places a higher demand on teachers' competencies. First, teachers' preparation time costs increase because different forms of interactive activities (including questionnaires, quizzes, drawings, fill-in-theblanks, web browsing, open-ended questions, etc.) must be included in the corresponding classroom knowledge, and these interactive activities need to satisfy not only the application of existing knowledge but also the rationality of their use [10]. Second, to adapt to the teaching style of the Nearpod platform, previous instructional designs may appear inappropriate for the Nearpod classroom. Hence, teachers need to make corresponding changes to the lesson structure and the design of classroom activities, which means that teachers need to reorganize all instructional content and instructional designs. Finally, any technical questions that arise in the classroom will require answers from the teacher, who must be aware of the technology challenges students may face in using it to help them engage successfully in synchronous and interactive classroom activities. Teachers, therefore, had to be trained in Internet Tools 2.0. The significance of this training is that teachers gain new information through professional and systematic training [9]. The new knowledge gained in Internet Tools 2.0 learning can help teachers carry out their daily teaching tasks better, become proficient in using different tools in different learning environments, and create new content with their students [15]. As more educators see the advantages of teaching aids such as the Nearpod platform, they leverage the tools for their teaching activities on a large scale. This has, to some extent, contributed to the process of technology innovation-driven educational development [15].

\section{CONCLUSION}

Synchronous engagement in secondary biology classrooms brings a better classroom experience for teachers and students. It gives us a more authentic classroom experience, especially during the special times when teaching has to be done online. Different students have different preferences for synchronous and asynchronous participation [16]. Synchronous remote 
participation in the classroom gave students the feeling of a traditional real classroom. They preferred this online interactive model that increased their sense of classroom participation compared to previous online education that faced cold electronic devices and virtual teacher influence. However, some students prefer asynchronous participation in the classroom because they can control the pace of their learning and have the freedom to schedule their study time. But the timely interaction of synchronous participation can provide more opportunities for students to communicate and collaborate. This is one of the advantages of using Nearpod applications for online teaching and learning.

The synchronous form of online learning and assessment can help teachers track student learning, and the Online Simultaneous Learning and Assessment Model (OLASF) impacts student performance. There is no denying that the traditional PowerPoint teaching model is an example of success in education with the help of technology tools, but there are some drawbacks if this teaching model is used in online teaching. Teachers are unable to understand students' learning in the classroom through real-time tests. Unlike the traditional PowerPoint teaching model, the neared-based real-time interactive teaching platform provides good two-way feedback for teachers and students. Also, Nearpod serves as a medium to provide continuous feedback to teachers and students, a good way to collect evidence of students' cognitive and non-cognitive achievements in online instruction, thus avoiding this situation and better-helping students interact with each other in the classroom, creating a virtuous cycle of teacher, student, and assessment. When feedback is effectively integrated with classroom instruction, it can contribute well to student learning. Students, especially with the help of timely feedback, can better build their interest in learning and gain a greater sense of learning achievement.

Nearpod platform motivates students to become more active in classroom activities. The real-time interactive classroom design ensures class participation and prevents students from using other programs in class to disrupt the class and the learning process to a certain extent. And the Nearpod app made the class-competitive and fun. When students are asked to present their answers in front of a large group of people, they tend to concentrate more on thinking and learn to perform well because they do not want to make any mistakes. However, the large-scale use of technology-based tools has to consider several realities. But this does not affect the popularity of Nearpod with more teachers and students in the future. In particular, a comparison of lower-performing students' test scores before Nearpod revealed more significant academic improvement. Student responses confirmed the relevance and value of Nearpod in the online classroom.

\section{REFERENCES}

[1] Harpp, D. N.; Fenster, A. E.; Schwarcz, J. A.; Zorychta, E.; Goodyer, N.; Hsiao, W.; Parente, J. (2004). Lecture retrieval via the Web: Better than being there? J. Chem. Educ., 81 (5), 688-690.

[2] Tsai, C. (2001). A review and discussion of epistemological commitments, metacognition, and critical thinking with suggestions on their enhancement in Internet-assisted chemistry classrooms. J. Chem. Educ, 78, 970-974.

[3] Mishra, P., \& Koehler, M. J. (2006). Technological Pedagogical Content Knowledge: A new framework for teacher knowledge. Teachers College Record, 108(6), 1017-1054.

[4] Delacruz, Stacy. (2014). Using Nearpod in elementary guided reading groups. TechTrends, 58(5), 62-69. https://doi.org/10.1007/s11528-0140787-9

[5] Buchanan, T. (2000). The efficacy of a world-wide web mediated formative assessment. Journal of Computer Assisted Learning, 16(3), 193-200.

[6] Amasha, M. A., \& Alkhalaf, S. (2016). Using RSS 2.00 as a model for u-learning to develop e-training in Saudi Arabia. International Journal of Information and Education Technology, 6(7), 516521.

[7] Beach, P. (2017). Self-directed online learning: A theoretical model for understanding elementary teachers' online learning experiences. Teaching and Teacher Education, 61, 60-72.

[8] Hattie, J., \& Timperley, H. (2007). The power of feedback. Review of Educational Research, 77(1), 81-112.

[9] Siegle, D. (2012). Embracing e-books: Increasing students' motivation to read and write. Gifted Child Today, 35(2), 137-143.

[10] Cochrane, T. D. (2010). Exploring mobile learning success factors. Research in Learning Technology, 18(2), 133-148.

[11] Larson, L. C. (2010). Digital readers: The next chapter in e-book reading and response. The Reading Teacher, 64(1), 15-22.

[12] Carrera, C. C., \& Asensio, L. A. B. (2016). Landscape interpretation with augmented reality and maps to improve spatial orientation skill. Journal of Geography in Higher Education, 41(1), 119-

133.https://doi.org/10.1021/acs.jchemed.0c00686 
[13] Kolb, D. A. (1984). Experiential Learning: Experience as the Source of Learning and Development. Englewood Cliffs, NJ: Prentice Hall.

[14] Dobson, J. L. (2008). The use of formative online quizzes to enhance class preparation and scores on summative exams. Advances in Physiology Education, 32(4), 297-302.

[15] Hao, Y., \& Lee, K. S. (2017). Inquiry of pre-service teachers' concern about integrating Web 2.0 into instruction. European Journal of Teacher Education, 40(2), 191-209. 